\title{
The role of reflection and reflexivity in the development of students' abilities
}

\author{
Vladimir D. Shadrikov \\ National Research University Higher School of Economics (HSE), Moscow, Russia
}

\begin{abstract}
This article analyzes different approaches to defining reflection and reflexivity. The mastery of intellectual operations reveals the role of reflexivity in the development of abilities. The operational aspect of reflection is emphasized in the article. The study is premised on the expectation that the effective realization of intellectual activities and the development of abilities determined by these activities are conditioned by adequate reflection on conscious acts directed toward the performance of educational-cognitive tasks.

The data from the experiment show that reflexivity as a personality trait is highly developed in students with high indexes of general intellectual operations. The research findings indicate the role of reflexive mechanisms in students' acquisition of intellectual abilities. The implications of these findings are discussed.
\end{abstract}

Keywords: activity subject, ability, reflection, reflectivity, development, intellectual operations

To define the role of reflexive mechanisms and to facilitate the acquisition of intellectual operations are the main tasks in developing abilities. In addressing these tasks, one needs to keep in mind two considerations. First, reflexivity as the basic element of subjectness ${ }^{*}$ is part of its structure. However, the series of experiments reported here shows that the process of students' subjectness and of their development of abilities has been inhibited by a low level of reflexivity development in all age groups. There is thus a need to investigate in detail the process of reflexivity formation in learning activities.

Second, the process of acquiring abilities and intellectual operations in learning activities is based on mechanisms of reflexive analysis of that activity and its separate components (motivation, goal, personal meaning, information base, decision

The results of the project "Investigation of the reflection role in the process of ability development," carried out within the framework of the Basic Research Program at the National Research University Higher School of Economics (HSE) in 2012, are presented in this article.

* I introduce this term in order to emphasize the essential property of subjects, a property that characterizes a subject's active beginning of an activity directed at achieving a goal. 
making, program, and implementation). One cannot consciously and intentionally develop abilities without reflection. The process is determined by students' analysis of their own mental acts, by understanding when and how to use certain intellectual operations, and also by understanding the consequences of doing so. Learning through ability development is based on reflexivity of intellectual activity. Reflection helps students acquire higher mental functions.

Authors who are interested in investigating personality traits have often referred to reflection as a process. They understand reflection to include such phenomena as self-awareness, rethinking and revising one's train of thought while doing something and estimating cause-effect relationships based on actions, words, or deeds that refer to a series of interconnected events.

The term reflection (from late Latin reflexio-'bent back') means introspection, comprehension, estimation of premises and conditions during the course of a person's activity and inner life. In philosophy reflection has been differently defined. The English philosopher John Locke defined reflection as a source of special cognition when the observation refers to an inner act of consciousness, but a sensation has outer things as its object. For the German philosopher Gottfried Wilhelm Leibniz, reflection is what we experience when we place our attention on what is happening within us. Carl Jung made an attempt to conceptualize reflection in terms of ideas. He defined ideas as the reflection on impressions gained from without (Frolov, 1986).

Taking into account this diversity of views regarding reflection, one has to conclude that reflection is characterized in general by its orientation to our inner world. This world is experienced with diverse features and manifestations, such as emotional states and feelings, shame experiences, and acts of consciousness (Shadrikov, 2006).

My research emphasizes the operational aspect of reflection. I believe that the effective realization of intellectual activity and the development of abilities determined by this activity are conditioned by adequate reflection of conscious acts directed toward the performance of educational-cognitive tasks. A student's orientation to an inward plan of intellectual activity can lead to the increased effectiveness of this activity and its further development and to reproduction in other conditions and situations.

To better understand the nature of reflection and its role in the development of cognitive ability, it is necessary to address the analysis of thinking activity, in the course of which the reflection of single mental processes (intellectual operations) and their results are realized. In the works of the great Russian scientist, philosopher, and psychologist Sergey Leonidovich Rubinshtein, the nature of a mental process reveals itself in an action or an act that is oriented toward performing a task. The task includes the goal of an individual's mental activity, which is correlated with the conditions set by that goal. Having been directed toward a goal or toward the performance of a task, the mental act of any subject ${ }^{*}$ is based on some of the subject's motives. The starting point of any mental process is usually a problem situation. Human thought operates only when it is directed by a need to understand something. A problem situation or an issue, a surprise or a perplexity or a contradiction

* By subject I mean any human being who is a source of activity. 
initiates thinking as a mental process. The person's involvement in the thinking process is defined by the problem situation. Thinking is always oriented to problem solving (Rubinshtein, 1958). In line with these considerations we can conceive that the beginning of thinking has to imply its ending. Thus, a problem solution is an innate end of the thinking process. If the goal is not reached, the subject will feel frustration or lack of success.

The dynamics of thinking are related to the emotional well-being of the "thinking subject," whose mental state is tense at the beginning and is contented or relaxed at the end. Generally, real thinking relates to the whole psychic life of an individual. Because thinking is closely associated with practice and is derived from a person's needs and concerns, emotional phenomena and feelings, which are expressed in subjective experience and a person's relationship to the surroundings, are joined in any intellectual process and make it expressive. To follow Rubinshtein's view (1995), it is not the thinking that thinks but a human being, so feelings occur in any thought.

Here I refer to Rubinshtein to underline key points for further understanding what thinking is. The first point is that one cannot analyze thinking without the thinking subject. It is the human being who thinks, rather than the thought. The person is involved in thinking. The second point is that any thinking, because of its structure, is an action directed toward the performance of a task. According to Rubinshtein, the needs and deeds of a person, the goal (which is part of the task), and the conditions (that set the task) are the elements that constitute the structure of action. The third point is that thinking arises through consciously regulated operations, or, more exactly, it is shaped by a system of intellectual operations. And the last, fourth, point is that consciousness of the thinking process is provided by critiques and checking. Rubinshtein (1995) pointed out that the whole flow of thinking is determined by a subject's awareness of the task that is performed during the thinking process. This process is experienced as the system of consciously regulated intellectual operations. Here, thinking, in contrast to any thought that might arise in the process of thinking, is correlated with the task that has to be performed by thinking and with the task's conditions.

In line with these points I believe that thinking as a process refers to thought production. Here I mean the thoughts that are further operated on by the subject in his or her thinking. In this context it is important to mention some suggestions of Rubinshtein and I. M. Sechenov, whose works have had an enormous influence on understanding the nature of thinking and the process of problem solving. To Rubinshtein (1958) a raised problem, in the whole set of its objective properties and principles, is involved in new relationships and thereby in making new relationships and characteristics that are fixed in new understandings. Thus, a problem is likely to draw out new content and is likely to be turned every time onto a new side. This is close to what Sechenov (1952) outlined by saying that each turn of a topic and drawing out of content is a new thought. Hence a set of thoughts characterizes the content of a topic. All these processes generate psychic content. Undoubtedly this content is enriched at the expense of assimilating ideas, but these same ideas are assimilated productively if they are associated with perceptions. 
To enrich the content of an action or deed, thinking works with psychic content, which might be consciously or unconsciously conceived. This work is done by using intellectual operations. The process is characterized by motives, goals, and by programming, decision-making (working with schemas), checking, and controlling processes.

In analyzing thinking as a psychic process I have intended to show that if one takes reflection out of thinking, it could be dissolved. So it is not possible to consider reflection as a separate process that is isolated from thinking. Thinking is not thought itself (it is not thinking about thinking). It operates as a mental function of the thinking subject and solves an important problem for him or her. The subject, by organizing mental activity, is aware of the problem-solving process and is guided by the idea of a result. Because the problem is solved by thinking, the subject becomes aware of the course of thought that is associated with the problem solving. So the subject learns to organize the course of his or her thoughts and to control them in accordance with the task conditions. This process is illustrated by the study of mathematics. The teacher of mathematics lessons trains students to learn. The generalized ability to track ones actions (mental and practical) and to determine their correctness turns into a personality trait. So we can assert that there is such a (generally acquired) personality trait as reflexivity.

Reflexivity is a personality trait that promotes the successful implementation of any activity by directing, organizing, and governing thinking. The person governs task performance and the course of his or her thoughts through reflexivity. Here I am concentrating on intellectual reflection, which reveals the course of the realization of the thinking processes. This type of reflection concerns knowledge about its object and methods of interacting with it. Intellectual reflection has been studied mainly in such fields as pedagogical and engineering psychology in connections with problems of organizing the cognitive processes of information processing and the development of ways of teaching how to solve typical problems.

Intellectual reflection forms the basis for the development of abilities through awareness of the mechanisms of implementation of one's intellectual operations and through generalizing the experience of their application in problem solving. To determine the influence of reflexive mechanisms on ability development, I focused on the dynamics of students' reflection development. Here are some considerations:

First, the basis of awareness is the generalization of the psychic processes that lead to their acquisition (Vigotsky, 1983). The general ability to reflect is formed in junior school students (from 6-7 to 10 years old) because of the sensitivity to learning that is peculiar to this age. Here reflection reveals itself through the students' control over their behavior, emotions, and needs and through their analysis of their thinking activity and current states of mind. The psychological peculiarities of children at this age, such as the unconditional acknowledgement of the teacher's authority, the belief in the truth of the knowledge they have to acquire, and their studiousness, enable them to enhance their receptivity to the educational task. Their mental activity is directed toward imitating their teacher and toward repeating the teacher's actions and statements. 
Second, for teenagers, the transition to a new stage is characterized by a change of inward preconditions, which are built over and to some extent repress previous preconditions. At the beginning of the teenage years, a child's interests transfer from an adult or a teacher, who has had authority over the child, to peers, who become more important to a child than they were before. Thus, the direction of reflection development moves from learning to personality. This movement is characterized by self-assessment and self-other assessment, by analysis of the processes of interpersonal interaction, and by the results of that interaction. Reflection development is kept out of learning. Teachers do not focus their attention mainly on this task.

Third, in the teenage years, consciousness is enriched and becomes systematic and ordered. Hence the development of reflexive processes is characterized by the establishment of the super-situational and cause-effect relationship. I have pointed out here that students' reflexivity or, in other words, their ability to reflect is spontaneously developed during their education. However, the students' ability to reflect is a foundation for self-control and self-analyzing, and, accordingly, for selfdevelopment. Undoubtedly, self-development should be an important educational goal for schools as well for society.

\section{Overview of the Experiment}

On the basis of the above analysis of the role of reflection and reflexivity in learning activities, I assumed that students' ability development depends on their reflection and reflexivity.

The research objectives:

1. To assess the level of reflexivity among students in the fourth grade with high and low indexes of general mental abilities.

2. To indicate a correlation between the level of reflection of separate intellectual operations and individual indexes of reflexivity among fourth-grade students.

3. To identify reflexivity development as the development of a personality trait among sixth-grade students.

These objectives defined the research strategy and its design, which were realized in a series of experiments.

\section{Method}

Participants: 138 students who studied at a large, metropolitan, comprehensive school. They were fourth-grade students, who were 8 to 10 years old ( $\mathrm{n}=47, \mathrm{M}=$ 8.89; $S D=0.76$ ), sixth-grade students, who were 10 to 12 years old ( $\mathrm{n}=49, \mathrm{M}=$ $11.04 ; S D=0.64)$, and tenth-grade students, who were 15 to 16 years old ( $\mathrm{n}=42$, $\mathrm{M}=15.48 ; S D=0.51$ ).

In the sixth and tenth grades the experiment was conducted during classes. Two groups of students from each grade level were selected: an experimental group and a control group. In order to assess the extent of the influence of students' development of intellectual operations on their reflection, the experimental group con- 
tained students who were engaged in the development of intellectual operations. The control group was not engaged in this way.

\section{Measures and Procedure}

At the present time there are many methods for diagnosing reflexive processes. Some of them are designed to diagnose single types and forms of reflection; others, to diagnose the level of reflective expression. In choosing the methods for the research I was guided by the principles of the system and activity approaches. I wanted to identify reflexivity development as a complete, single, and integral process. Nowadays the integrative (system) property of reflexive ability is being studied by Anatoly V. Karpov, Irina M. Skityaeva, and Vaveriya V. Ponomareva. Based on a system-activity approach, Karpov (2004) has defined reflexivity as a professionally significant trait of the activity subject. By reflexivity he means the ability that is characterized by having a measure of expressiveness that can be identified in certain psychometric procedures. In line with this statement I used the method of diagnosing the level of the development of reflexivity (Karpov, 2003). The method is designed to assess three reflexivity types:

- situational reflection, which supports control of one's behavior in actual situations

- retrospective reflection, which supports the analysis of activities that were engaged in previously and events that have already happened

- perspective reflection, which supports the analysis of future activity by making plans for the future

A questionnaire contained 27 questions: direct questions (15) and reversed questions (12). The participants were asked to choose the correct answer from among seven possible answers:

1 - absolutely incorrect

2 - incorrect

3 - incorrect then correct

4 - do not know

5 - correct then incorrect

6 - correct

7 - absolutely correct

After testing, the participants' answers were transformed into a sten scale to process the empirical data.

Moreover I also used the test method designed by Livio Antonio da Silva (2010) in his dissertation research under my guidance. The method contains some tasks and a series of follow-on questions that are designed to identify the level of the involvement of reflexive mechanisms in the process of intellectual problem solving. The answers were assessed on a 4-point scale. The sum of each participant's points indicates the actual level of reflection on intellectual operations. The tasks were developed for fourth-grade students on the basis of their knowledge, capacities, and skills. The results were used to form the sample of fourth-grade students. 


\section{Results}

Initially the level of reflexivity development as a personality trait among the fourthgrade students with high and low indexes of general intellectual abilities was analyzed. Figure 1 displays the results of testing. The average score for the group of students with low IQ indices was 103.5 points. According to Karpov's method, this result corresponds to 2 stens. This is evidence of a low level of reflexivity development. The scores for the group of students with a high level of intellectual ability corresponded to 3 stens. This is evidence of a moderately low level of reflexivity development. Thus in both groups of fourth-grade students the level of reflexivity development was below average.

Let's now have a look at the intercorrelation between the reflexivity level of single intellectual operations and the individual level of reflexivity among fourthgrade students. Karpov's method of diagnosing reflexivity development and the method for investigating the level of reflexivity for single intellectual operations (da Silva, 2010) were used to calculate the individual reflexivity level. In Figure 2 the final assessments of both analyzed indexes are expressed in a group profile. Thus, the higher a student's index is using one of the methods, the higher it is using the other method. The correlation between indexes of both methods is $r=0.82(p=0.001)$.

Figure 3 presents a comparative analysis of reflexivity levels in the experimental groups and the control groups of the sixth- and tenth-grade students.

The average level of reflexivity in both groups of sixth- and tenth-grade students was lower than that for the fourth-grade students with high IQs. In the sixth grade, the students in the control group, who had not been engaged in the development of intellectual operations, demonstrated an average level of reflexivity corresponding to 2 stens, evidence of the lowest level of reflexivity development. The students in the experimental group, who had been engaged in the development of intellectual operations, demonstrated a reflexivity level on the border of 3 stens. This result indicates the lowest level of reflexivity.

This tendency is more evident in the tenth grade. The students in the control group had average scores corresponding to 1 sten, while the students in the experimental group had average scores corresponding to 2 stens.

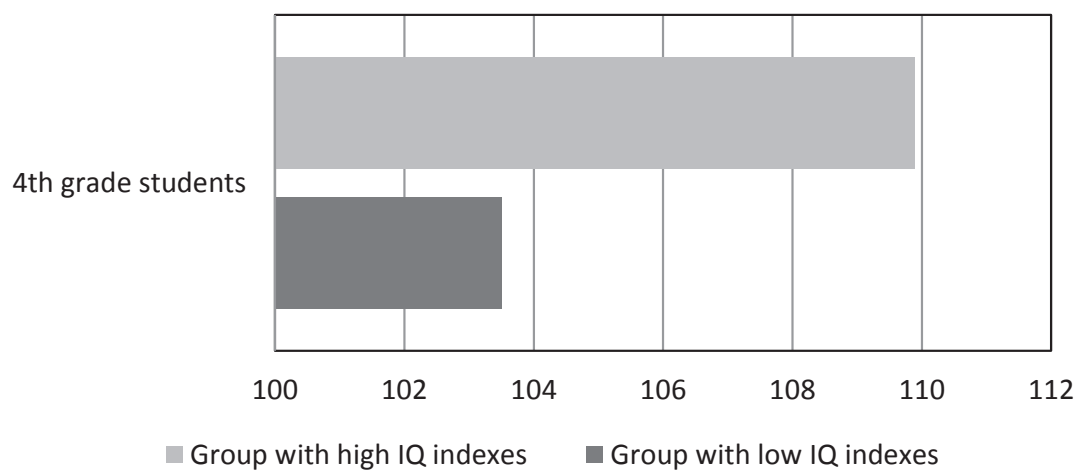

Figure 1. Level of reflexivity among fourth-grade students with high and low indexes of general intellectual abilities $(\mathrm{N}=47)$. 


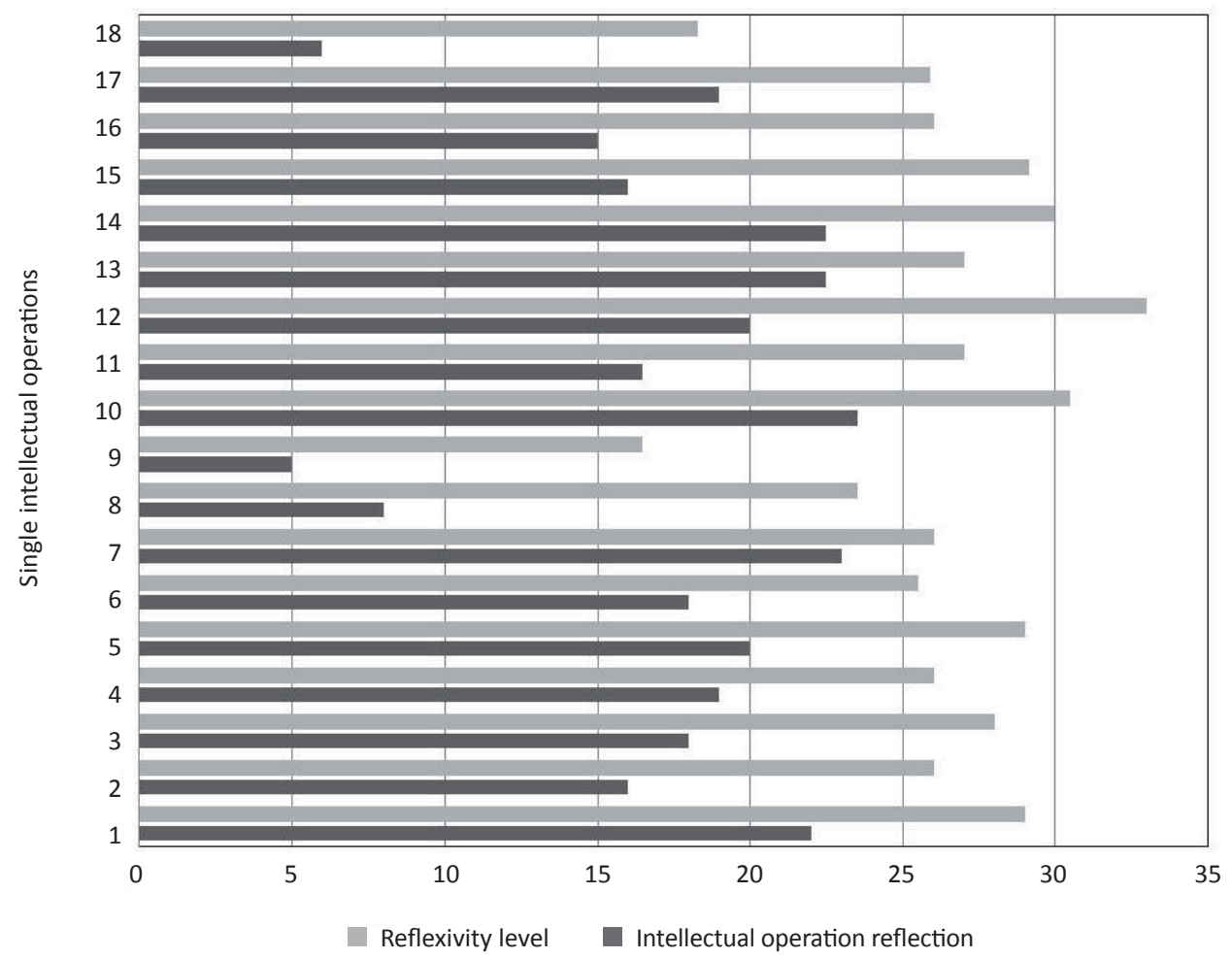

Figure 2. Comparative analysis of intellectual reflexivity and individual reflexivity of fourthgrade students.

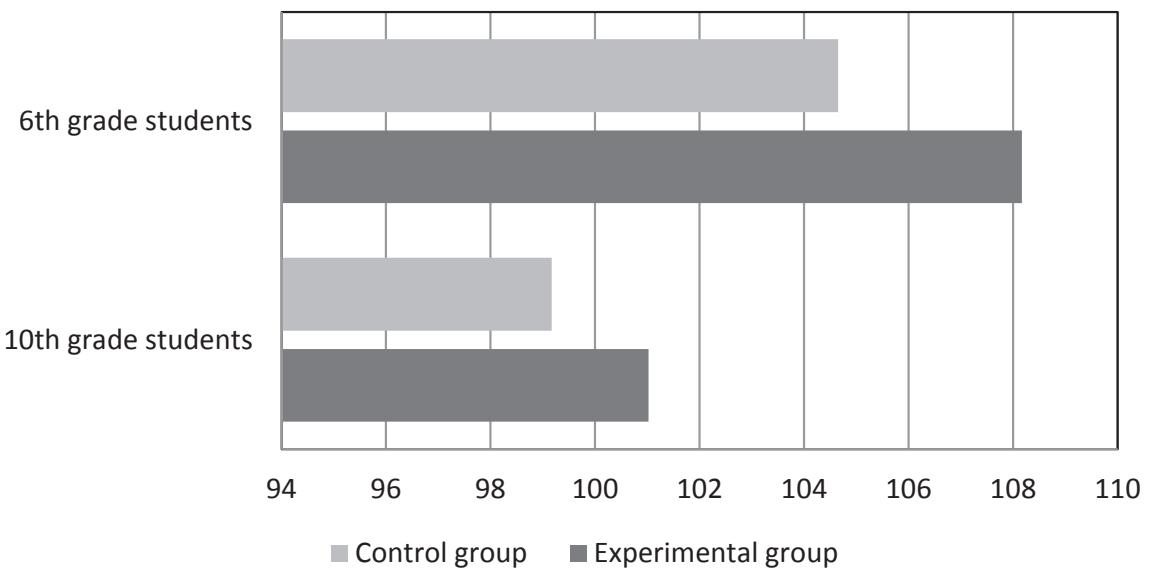

Figure 3. Reflexivity level in experimental and control groups of sixth-grade and tenth-grade students. 


\section{Discussion}

The experimental data show that reflexivity as a personality trait was highly developed in the fourth-grade students with high indexes of general intellectual operations. This finding raises the question of whether high intellectual development determines students' reflection or whether the development of reflection determines students' intelligence. In keeping with the results of my previous research, which have indicated significant correlations between the indexes of reflexivity and the indexes of intellectual operations, it might be said that reflexivity and intellectual development mutually correlate. In my research I also have found that the more students express their individual reflexivity, the more they express their ability to reflect on their intellectual operations. So we can conclude that the level of reflexivity development depends on general intellectual abilities. In the process of the development of abilities through the acquisition of intellectual operations, the reflexivity level is expressed by the successful acquisition of single intellectual operations and consequently of abilities in general. The research data presented here indicate that students' acquisition of intellectual operations should be followed by the development of their reflexivity.

It appears nowadays that the development of reflexivity mechanisms in the learning process is one of the perspective ways to heighten the quality of education by developing students' abilities, capacities, and skills to perform intellectual tasks. At the same time it is evident that reflexivity development is not regarded as an important objective that teachers aim to reach in the learning process. It is important to study this aspect of teachers' activity in order to enhance the quality of students' training in the early stages of their education. The parents' role here is also important, particularly if the school cannot provide reflexivity development. There are many tasks that are directed toward forming reflection and toward developing it in junior-school-age children. One can have conversations with children that include, for example, the analysis of literature, current events, deeds, and reactions of other people. So, as has been shown, the spectrum of instrumental means might be enough; however, their importance in developing a child's intellectual potential should be accentuated.

If we look at reflexivity development as a personality trait among sixth- and tenth-grade students, we can see that the reflexivity level has a tendency not to increase but to decrease. In addition, the students in the experimental groups, who had undergone for some years the development of intellectual operations, demonstrated the highest level of reflection. Thus in the development of abilities special work needs to be done in comprehensive schools on the formation of students' reflexivity. This conclusion is a matter of principle in my research; it underlines the impact of purposeful work on the development of reflection. Based on the significance of reflexivity mechanisms in the developmental process and in the selfdevelopment of students and on their awareness of their own possibilities and areas of potential growth, this proposal is an important signal to a system of education that does not traditionally give enough attention to this issue. Task-oriented work on the development of intellectual abilities enables proper and substantial changes in students' development. 


\section{References}

da Silva, L. A. (2010). Razvitie refleksii kak uslovie ovladeniya intelectual'alnimi operatsiyami [Reflection development as a condition for the acquisition of intellectual operations] (Unpublished doctoral dissertation). Moscow Pedagogical State University. Moscow.

Frolov, I. T. (Ed.). (1986). Filosofski slovar [Philosophical dictionary]. Moscow: Politizdat.

Karpov, A. V. (2003). Reflecsivnost' kak psihicheskoe svoystvo i metodika eyo diagnostiki [Reflection as a psychic property and a method for diagnosing it]. Psihologicheskiy Zhurnal [Psychological journal], 5(24), 45-57.

Karpov, A. V. (2004). Psihologiya reflecsivnih mehanizmov deyatelnosti [The psychology of reflexivity mechanisms]. Moscow: Institut Psihologii RAN.

Rubinshtein, S. L. (1958). O mishlenii i putyah ego isledovaniya [About thinking and ways of studying it]. Moscow: Akademiya Nauk SSSR.

Rubinshtein, S. L. (1995). Osnovi obshei psihologii [Foundations of general psychology]. Moscow: Piter.

Sechenov, I. M. (1952). Elementi misli [Elements of thought]. In H. K. Kashtayantsa (Ed.), Izbranie proizvedeniya [Selected works] (Vol. 1, pp. 272-426). Moscow: Akademiya Nauk SSSR.

Shadrikov, V. D. (2006). Intelectual'nie operatsii [Intellectual Operations]. Moscow: Logos.

Shadrikov, V. D. (2006). Mir vnutreney zhizni cheloveka [The world of man's inner life]. Moscow: Logos.

Vigotsky, L. S. (1983). Sobraniye sochineniy [Collected works] (Vol. 3). Moscow: Pedagogika. 